\title{
Botulinum toxin type-A (BoNTA) and dynamic wrist-hand orthoses versus orthoses alone for the treatment of spastic-paretic upper extremity in chronic stroke patients
}

\author{
Sepideh Pooyania*, Brenda Semenko \\ Riverview Health Centre, University of Manitoba, Winnipeg, Canada; ${ }^{*}$ Corresponding Author: spooyania@rhc.mb.ca
}

Received 29 November 2013; revised 4 January 2014; accepted 15 January 2014

Copyright (C) 2014 Sepideh Pooyania, Brenda Semenko. This is an open access article distributed under the Creative Commons Attribution License, which permits unrestricted use, distribution, and reproduction in any medium, provided the original work is properly cited. In accordance of the Creative Commons Attribution License all Copyrights (C) 2014 are reserved for SCIRP and the owner of the intellectual property Sepideh Pooyania, Brenda Semenko. All Copyright @ $C 2014$ are guarded by law and by SCIRP as a guardian.

\section{ABSTRACT}

Purpose: The purpose of this study was to investigate the potential functional improvement of the spastic-paretic upper extremity of individuals with chronic hemiparesis when using a dynamic wrist-hand orthosis with and without concurrent botulinum toxin type-A (BoNTA) injections into the spastic upper extremity muscles. Methods: A three-year retrospective chart review was conducted on all stroke patients referred to out-patient occupational therapy for an upper extremity rehabilitation program, which included use of a dynamic wrist-hand orthosis (DWHO). Three charts documented concurrent treatment with a DWHO + BoNTA. Eleven charts documented DWHO use without concurrent BoNTA treatment. Pre- and post-intervention outcome measure scores were compared between the two groups. Pre- and post-intervention scores were also analyzed irrespective of treatment group. Results: Although improvement approached significance on three of the documented outcome measures when comparing the DWHO + BoNTA and DWHO groups, no statistically significant changes were found. A significant difference $(p<0.05)$ however, was found between the pre- and post-intervention scores irrespective of treatment group in $\mathbf{1 3}$ of 14 of the outcome measures documented. Conclusions: Further research with a larger sample size is suggested to assess the combined effect of using a dynamic wrist-hand orthosis and BoNTA injections into the spastic upper extremity muscles of individuals with chronic hemiparesis post stroke.

\section{KEYWORDS}

Stroke Rehabilitation; Botulinum Toxin;

Orthosis

\section{INTRODUCTION}

Cerebrovascular disorders represent the third leading cause of mortality and the second major cause of long term disability in North America. Upper extremity complications are common following stroke and may be seriously debilitating. For those upper extremities with signs of recovery, consensus opinion is that attempts to restore function through therapy should be made [1].

Task specific training has been shown to facilitate the recovery of upper extremity function [2-6] and to influence long term cortical reorganization $[7,8]$. Rehabilitation efforts that maximize the extent of cortical reorganization appear to demonstrate the greatest chance of achieving success in functional outcomes [9]. The Canadian Best Practice Recommendations for Stroke Care (2010) for Management of the Arm and Hand (Section 5.4.1) [10] state that therapy should consist of: "repetitive and intense use of novel tasks that challenge the patient to acquire necessary motor skills to use the involved limb during functional tasks and activities (Evidence Levels: Early_Level A, Late-Level A)." Constraint induced 
movement therapy (CIMT) is one treatment approach that has received much attention in recent years and involves performing intense repetitive task specific training with the paretic side [11-16], however, participants must demonstrate at least 10 degrees of active finger and wrist extension to qualify. Up to $40 \%$ of stroke survivors however have more severe motor impairment of the more-affected arm in the chronic phase [13-17]. This motor impairment results in substantial reductions in independence and quality of life [18]. There is the potential for further functional improvement in some individuals with moderate to severe post stroke hemiparesis; even in the long-term stage of recovery $[19,20]$. Limited treatment strategies are available, however, that incorporate repetitive task specific training for patients with some active shoulder and elbow movement but little active hand movement.

Dynamic wrist-hand orthoses (DWHO) are specifically designed to position a non-functional hand at optimal biomechanical advantage so that grasp and release activities are possible [21]. Following volitional recruitment of the thumb and finger flexors, the patient subsequently relaxes the flexors to allow the extension spring system to assist with reopening the hand. The DWHO allows patients with moderate to severe upper extremity hemiparesis to participate in task specific training activities that they would otherwise be unable to do [22].

In a pilot clinical trial by Jeon et al., the experimental group used a spring assisted DWHO one hour per day, five times a week for four weeks. The control group wore the same orthosis for one hour per day without participating in upper extremity training. The experimental group showed significant improvement on several outcome measures of upper extremity function compared to the control group [23]. Barry et al. found that a higher number of grasp-release repetitions led to greater functional change in patients with chronic hemiparesis [19].

Focal spasticity is a common complication post stroke. Broeks et al. noted that $83 \%$ of patients at four years post stroke had some degree of abnormal tone, with $41 \%$ exhibiting moderately and 9\% exhibiting severely increased tone [24]. For some patients, moderate to severe focal spasticity in the elbow, wrist and/or finger flexors may make it difficult to use and receive optimal benefit from a DWHO.

One treatment commonly used for spasticity management of the upper extremity is botulinum toxin type-A (BoNTA) injections into the spastic muscles. Extensive clinical experience with BoNTA has shown it to be well tolerated and associated with few adverse events across a variety of indications [25]. A meta-analysis of 37 studies has confirmed the excellent safety profile of BOTOX (R) (grade A evidence) which continues with long-term use
[26]. An evidence based review of the use of botulinum neurotoxin for the treatment of spasticity concluded that botulinum toxin is an effective treatment of adult spasticity in the upper limbs; that it reduces muscle tone and improves passive function [27].

The link between botulinum toxin and functional gain remains unclear. In a summary of results from several randomized control trials and systematic reviews examining the use of botulinum toxin as a treatment for post stroke spasticity, Teasell et al. concluded that treatment with botulinum toxin "has yet to be established as being effective in improving functional outcomes in the majority of treated patients" post stroke [28]. Although it has been shown that botulinum toxin treatment successfully reduces spasticity, the overall "impact on function is either small or has yet to be determined" [28].

To optimize upper extremity recovery post stroke, it makes sense that repetitive task specific training be combined with botulinum toxin for patients with moderate to severe spasticity. Botulinum toxin injections as a precursor to a defined exercise program may not impact function more than the exercise program itself [29], however, combining the injections with intensive task practice such as modified constraint movement therapy has shown some encouraging results [30]. Botulinum toxin injections may allow patients to more fully participate in the selected therapy programs. Following injection, injected muscles can be stretched in therapy and antagonist muscles can be strengthened [31]. Spasticity management involves a multi-disciplinary team approach that includes an active program of occupational or physiotherapy, with one aim being to improve motor training to increase active participation in tasks [32].

Dynamic wrist-hand orthoses have been used regularly since 2010 by occupational therapists in a Canadian outpatient stroke program as a way of promoting increased repetitive task specific use of the affected upper extremity. It was noted by therapists that some patients had difficulty using the orthosis due to moderate-severe spasticity in the hemiparetic upper extremity. These patients therefore had difficulty participating in the recommended repetitive task specific training activities. The therapists hoped that injection with botulinum toxin into the spastic muscles would decrease the amount of spasticity thereby allowing easier use of the DWHO for task specific training, as well as potentially unmask active movement to allow concurrent strengthening of the antagonist muscles post injection.

The purpose of this retrospective study was to investigate the potential functional improvement of the spasticparetic upper extremity of individuals with chronic hemiparesis when using a dynamic wrist-hand orthosis with and without concurrent BoNTA injections into the spastic 
upper extremity muscles.

\section{METHODS}

The study protocol was approved by the hospital ethics committee. A three year retrospective chart review was conducted on all stroke patients referred to out-patient occupational therapy (OT) for an upper extremity rehabilitation program, which included the use of a dynamic wrist-hand orthosis, i.e. SaeboFlex ${ }^{\mathrm{TM}}$. Pre- and post-intervention measures were recorded, as available, using a data collection form. Active range of motion including: shoulder flexion/abduction, elbow flexion/extension, wrist flexion/extension, and finger flexion/extension were documented. Due to the varied type of documentation describing active finger flexion and extension (including descriptive and goniometric measurement) results were converted into a 0 - 4 ordinal scale, i.e., $0=$ no active flexion/extension, 4 = full active flexion/extension (see Table 1). Documentation regarding active thumb range of motion was recorded when available. Grip strength and lateral pinch strength scores, Modified Ashworth Scale (MAS) scores for elbow, wrist and finger flexors (summed), Fugl Meyer Upper Extremity (FMA-UE) scores and the Canadian Occupational Performance Measure (COPM) scores (Performance and Satisfaction) were also recorded as available. Patients who received concurrent BoNTA injections were noted; targeted muscles and dates of injection were recorded. Time since stroke, number of OT visits, and frequency of use at home were also recorded.

Statistical analysis of data was completed. Using the Wilcoxon rank-sum test, the change scores (i.e., postintervention minus pre-intervention for each subject) between the two treatment groups were compared. Thumb active range of motion was not analyzed statistically due to its descriptive nature and inconsistent documentation in the charts reviewed. Meanwhile, the Wilcoxon signed-rank test for paired data assessed for significant differences between pre- and post-intervention change scores irrespective of treatment group. Non-parametric tests were deemed appropriate given the small sample sizes and, in some cases, ordinal outcomes.

\section{RESULTS}

Fourteen charts were reviewed (12 males, 2 females; mean age: 56 years). Table 2 shows the demographic and clinical characteristics of the fourteen patients who were included. Three charts documented concurrent treatment with DWHO + BoNTA and eleven charts documented DWHO use without concurrent BoNTA treatment. For those that received BoNTA injections, the targeted muscle groups included: elbow flexors, elbow extensors, pronators, wrist flexors, finger flexors, thumb flexors and
Table 1. Finger flexion/extension.

\begin{tabular}{cc}
\hline Scale & Description \\
\hline 4 & Full active movement \\
3 & $3 / 4$ of full active movement \\
2 & $1 / 2$ of full active movement \\
1 & $1 / 4$ of full active movement \\
0 & No active movement \\
\hline
\end{tabular}

hand intrinsics. Mean time since stroke onset was 43.7 months for the DWHO + BoNTA group and 20.1 months for the DWHO only group. Mean number of OT visits was 29.3 visits for the DWHO + BoNTA group and 33.2 visits for the DWHO only group.

When comparing the DWHO + BoNTA to the DWHO only group, improvement approached significance for elbow extension $(p=0.0671$ ) (Table 3$)$. Mean summed MAS scores improved from 6.67 to 4.33 (DWHO + BoNTA) and from 3.73 to 2.18 (DWHO only). It was noted that Lateral Pinch strength and Fugl Meyer Upper Extremity scores approached significance $(p=0.0560$ and $\mathrm{p}=0.0577$ respectively) when comparing the DWHO only group to the DWHO + BoNTA group (Table 3), however no significant differences were found between the two groups. Meanwhile, change scores irrespective of treatment group were also analyzed. As the data suggests, both groups improved significantly from pre- to postintervention assessment on 13 out of 14 of the outcome measures documented (Table 4).

\section{DISCUSSION}

No significant differences were found between the DWHO only group and the DWHO + BoNTA groups when comparing the pre- and post-outcome measure scores from this retrospective chart review. Because of the small sample size and variability in size of the two groups, comparison between the groups was difficult.

As the data suggests, however, both groups improved significantly from pre- to post-intervention assessment on 13 out of 14 of the outcome measures documented. Patients who used the DWHO for repetitive task oriented training, with and without BoNTA, demonstrated improvement on the documented outcome measures.

It was noted that lateral pinch strength and Fugl Meyer UE scores approached significance when comparing prepost changes between the DWHO and the DWHO + BoNTA group. We know that the DWHO only group had lower summed MAS scores initially as well as earlier use of the DWHO in therapy and therefore had potentially higher functioning upper extremities to start with. It is suspected that certain outcome measures, such as these, may be more sensitive to change when the limb is higher functioning. The DWHO + BoNTA group began therapy 
Table 2. Patient demographics.

\begin{tabular}{|c|c|c|c|c|c|c|c|}
\hline Patient & Gender & Age (years) & $\begin{array}{l}\text { Paretic } \\
\text { Side }\end{array}$ & $\begin{array}{l}\text { Dominant } \\
\text { Side }\end{array}$ & $\begin{array}{l}\text { Time since stroke } \\
\text { (months) }\end{array}$ & Number of OT visits & $\begin{array}{c}\text { Frequency of } \\
\text { orthosis use at home }\end{array}$ \\
\hline 1 & M & 58 & $\mathrm{R}$ & $\mathrm{R}$ & 31 & 49 & $2-5$ \\
\hline 2 & M & 76 & $\mathrm{~L}$ & $\mathrm{R}$ & 9 & 17 & 14 \\
\hline 3 & M & 21 & $\mathrm{R}$ & $\mathrm{R}$ & 17 & 41 & $2-4$ \\
\hline $4^{\dagger}$ & $\mathrm{F}$ & 53 & $\mathrm{~L}$ & $\mathrm{R}$ & 74 & 18 & $2-3$ \\
\hline 5 & M & 44 & $\mathrm{~L}$ & $\mathrm{R}$ & 73 & 37 & $1-4$ \\
\hline 6 & M & 58 & $\mathrm{R}$ & $\mathrm{R}$ & 15 & 33 & $4-6$ \\
\hline 7 & M & 51 & $\mathrm{~L}$ & $\mathrm{R}$ & 12 & 63 & $2-3$ \\
\hline 8 & M & 55 & $\mathrm{~L}$ & $\mathrm{R}$ & 26 & 18 & $2-3$ \\
\hline 9 & M & 70 & $\mathrm{R}$ & $\mathrm{R}$ & 10 & 22 & $4-7$ \\
\hline $10^{\dagger}$ & M & 59 & $\mathrm{~L}$ & $\mathrm{R}$ & 35 & 19 & $1-3$ \\
\hline $11^{\dagger}$ & M & 48 & $\mathrm{~L}$ & $\mathrm{R}$ & 22 & 51 & $1-2$ \\
\hline 12 & M & 74 & $\mathrm{~L}$ & $\mathrm{R}$ & 12 & 17 & $5-6$ \\
\hline 13 & $\mathrm{M}$ & 70 & $\mathrm{~L}$ & $\mathrm{R}$ & 9 & 31 & 7 \\
\hline 14 & F & 48 & $\mathrm{R}$ & $\mathrm{L}$ & 7 & 37 & $5-7$ \\
\hline
\end{tabular}

Abbreviations: M, male; F, female; R, right; L, left. ${ }^{*}$ Times used per week. ${ }^{\dagger}$ Patients received concurrent BoNTA and SaeboFlex treatment.

Table 3. Change score comparisons (post-intervention minus pre-intervention between treatment groups).

\begin{tabular}{|c|c|c|c|}
\hline Measure & $\begin{array}{c}\text { SaeboFlex + BoNTA }(n=3) \\
\text { Median/Mean } \pm \text { SD }\end{array}$ & $\begin{array}{l}\text { SaeboFlex only }(\mathrm{n}=11) \\
\text { Median/Mean } \pm \text { SD }\end{array}$ & $\begin{array}{l}\text { Wilcoxon } \\
\text { p-value }^{\dagger}\end{array}$ \\
\hline Shoulder Flexion (deg) & $35.00 / 33.33 \pm 22.55$ & $35.00 / 42.27 \pm 27.51$ & 0.7597 \\
\hline Shoulder Abduction (deg) & $25.00 / 25.00 \pm 10.00$ & $20.00 / 21.36 \pm 15.51$ & 0.7579 \\
\hline Elbow Flexion (deg) & $0 / 6.67 \pm 11.55$ & $5.00 / 6.36 \pm 10.51$ & 0.8689 \\
\hline Elbow Extension (deg) & $-35.0 /-28.33 \pm 16.07$ & $0 /-6.36 \pm 13.62$ & 0.0671 \\
\hline Wrist Flexion (deg) & $0 / 10.00 \pm 17.32$ & $0 / 6.36 \pm 9.24$ & 1.0000 \\
\hline Wrist Extension (deg) & $15.00 / 16.67 \pm 12.58$ & $15.00 / 16.82 \pm 13.09$ & 1.0000 \\
\hline Finger Flexion (deg) & $0 \pm 0$ & $0 / 0.36 \pm 0.50$ & 0.2948 \\
\hline Finger Extension (deg) & $1.00 / 1.33 \pm 0.58$ & $1.00 / 1.36 \pm 0.67$ & 0.9320 \\
\hline Grip Strength (kg) & $3.00 / 3.27 \pm 2.61$ & $3.00 / 4.29 \pm 3.45$ & 0.8684 \\
\hline Summed Modified Ashworth Scale & $-2.00 /-2.33 \pm 0.58$ & $-1.00 /-1.55 \pm 1.04$ & 0.1589 \\
\hline Fugl Meyer Upper Extremity ${ }^{*}$ & $0.11 / 0.12 \pm 0.03$ & $0.20 / 0.22 \pm 0.07$ & 0.0577 \\
\hline COPM: Performance & $3.60 / 2.87 \pm 1.63$ & $3.40 / 2.86 \pm 1.49$ & 0.7602 \\
\hline COPM: Satisfaction & $4.00 / 3.40 \pm 1.40$ & $2.60 / 2.69 \pm 1.49$ & 0.5438 \\
\hline
\end{tabular}

Abbreviation: COPM, Canadian Occupational Performance Measure. *Fugl Meyer Upper Extremity scores were converted to a percentage. ${ }^{\dagger}$ Wilcoxon ranksum test comparing group change scores $(\mathrm{p}<0.05)$.

in more chronic stages of their spasticity, 43.7 months versus 20.1 months. Although information on tissue shortening and contracture were not collected, given the length of time post stroke, it is presumed this may have occurred to some degree. It was not unexpected, therefore, to see more improvement in some of the outcome measures in the DWHO only group. This may emphasize a very important clinical point in spasticity treatment. It is more challenging to treat spasticity and achieve the desirable functional goal in more chronic cases.

It is interesting to consider why more of the patients in this study were not referred for BoNTA injections. Certainly the data indicates that those with higher summed MAS scores initially (mean $=6.67$ for the DWHO + BoNTA group vs. mean $=3.73$ for the DWHO only group), and therefore potentially lower functioning upper extremities, were the ones who met with the physiatrist and ultimately received BoNTA injections. Due to the 
Table 4. Overall change scores (post-intervention-pre-intervention irrespective of treatment group).

\begin{tabular}{ccc}
\hline Measure & Median/Mean \pm SD & Wilcoxon P value $^{\dagger}$ \\
\hline Shoulder Flexion (deg) & $35.00 / 40.36 \pm 25.98$ & 0.0001 \\
Shoulder Abduction (deg) & $22.50 / 22.14 \pm 14.24$ & 0.0005 \\
Elbow Flexion (deg) & $2.50 / 6.43 \pm 10.27$ & 0.0156 \\
Elbow Extension (deg) & $-2.50 /-11.07 \pm 16.43$ & 0.0156 \\
Wrist Flexion (deg) & $0.00 / 7.14 \pm 10.69$ & 0.0313 \\
Wrist Extension (deg) & $15.00 / 16.79 \pm 12.50$ & 0.0002 \\
Finger Flexion (deg) & $0.00 / 0.29 \pm 0.47$ & 0.1250 \\
Finger Extension (deg) & $1.00 / 1.36 \pm 0.63$ & 0.0002 \\
Grip Strength (kg) & $3.00 / 4.05 \pm 3.21$ & 0.0005 \\
Lateral Pinch Strength (kg) & $1.50 / 1.45 \pm 0.86$ & 0.0005 \\
Summed Modified Ashworth Scale & $-2.00 /-1.71 \pm 0.99$ & 0.0002 \\
Fugl Meyer Upper Extremity & $0.18 / 0.19 \pm 0.08$ & 0.0010 \\
COPM: Performance & $3.50 / 2.86 \pm 1.46$ & 0.0001 \\
COPM: Satisfaction & $2.80 / 2.84 \pm 1.45$ & 0.0001 \\
\hline
\end{tabular}

Abbreviations: COPM, Canadian Occupational Performance Measure; kg, kilograms; deg, degrees. ${ }^{*}$ Fugl Meyer Upper Extremity scores were converted to a percentage. ${ }^{\dagger}$ Wilcoxon signed-rank test for paired data $(\mathrm{p}<0.05)$.

nature of this retrospective study, all discharged charts from patients who had used SaeboFlex ${ }^{\mathrm{TM}}$ as part of their occupational therapy outpatient program were reviewed, regardless of the amount of active movement and/or spasticity observed in the upper extremity. This resulted in great variability between patients in the amount of active movement, spasticity and functional ability of the hemiparetic upper extremity at the pre- and post-intervention assessments. It is important to note that summed MAS scores were noted to improve in both groups, regardless of BoNTA injection.

It was noted that the number of OT visits was similar between the two groups, although great variability was seen when looking at both groups together (range of 17 63 visits). Documentation indicated that OT visits were used for other OT assessments and interventions typically required post stroke, however, the focus of the majority of the sessions appeared to be on repetitive grasprelease upper extremity retraining.

Use of the DWHO at home between OT sessions was variable within and between the groups and was not reported in a consistent manner in the charts reviewed, making comparison between the two groups difficult. It was noted in both groups that the majority of the patients did not use the DWHO the recommended twice a day that the orthosis is intended to be used and some used it minimally between OT treatment sessions. Only one patient was noted to use the DWHO the suggested number of times per week. The patients who did not use their orthosis daily at home obviously lacked the intensity of repetition thought to be required for optimal recovery. The amount of time the DWHO was used in a single treatment session was not recorded.

Despite the frequent use of BoNTA injections for spasticity management and the increasing use of dynamic wrist-hand orthoses to facilitate task specific training post stroke, the combined use of these two treatment modalities has not previously been studied. This is the first study that looks at the combined use of the SaeboFlex $^{\mathrm{TM}}$ orthosis and BoNTA.

\section{LIMITATIONS}

One limitation of this study is the relatively small number of charts reviewed and the small size of the DWHO + BoNTA group compared to the DWHO only group. The DWHO + BoNTA group was more chronic than the DWHO only group; possibly introducing confounding factors such as tissue shortening, contracture, and learned non-use. These factors, although not formally measured in this study, may have impacted the amount of functional improvement made.

Furthermore, although all charts reported results of hemiparetic upper extremity therapy, there was large variation in the level of hemiparesis, amount of spasticity and subsequent functional abilities of the limb. Patients were not categorized based on their level of hemiparesis. Therefore, although patients were noted to improve on several of the outcome measures, the amount of improvement varied considerably between patients, making comparison difficult.

Use of the DWHO at home was not consistently reported for either group; therefore the influence of adherence to the home program could not be determined.

An additional limitation of the study is that we were 
unable to identify particular muscle groups/dosages that would most benefit from BoNTA injection for those using a SaeboFlex ${ }^{\mathrm{TM}}$ orthosis in therapy. It has been noted in treatment sessions that a temporary disruption in the SaeboFlex $^{\mathrm{TM}}$ therapy training program may occur with maximum dosage injection to flexor digitorium superficialis (FDS) and flexor pollicis brevis (FPB), the primary flexors used to operate the Saebo Flex orthosis. In chronic cases of spasticity, however, it may be necessary to target these two muscles with the maximum dosage for optimal spasticity management and functional gain.

\section{CONCLUSION}

The findings of this study indicate that for some patients with chronic upper extremity hemiparesis post stroke, there is the potential for further functional improvement using a dynamic wrist-hand orthosis for repetitive grasp-release training; however the use of concurrent BoNTA injections for those with moderate-severe spasticity, in facilitating use of the orthosis remains unclear. Further research with a larger, more homogeneous sample is suggested to assess the combined effect of using a dynamic wrist-hand orthosis and BoNTA injections into the spastic upper extremity muscles.

\section{ACKNOWLEDGEMENTS}

This study is supported with unrestricted research funds from Allergan Canada.

\section{REFERENCES}

[1] Evidence based review of stroke rehabilitation. (2013). http://www.ebrsr.com/reviews_details.php?Clinical-Cons equences-of-Stroke-13

[2] Van Peppen, R.P.S., Kwakkel, G., Wood-Dauphinee, S., Hendriks, H.J.M., Van der Wees, P.J. and Dekker, J. (2004) The impact of physical therapy on functional outcomes after stroke: What's the evidence? Clinical Rehabilitation, 18, 833-862. http://dx.doi.org/10.1191/0269215504cr843oa

[3] Oujamaa, L., Relave, I., Froger, J., Mottet, D. and Pelissier, J. (2009) Rehabilitation of arm function after stroke. Literature review. Annals of Physical and Rehabil Medicine, 52, 269-293.

http://dx.doi.org/10.1016/j.rehab.2008.10.003

[4] Thielman, G.T., Dean, C.M. and Gentile, A.M. (2004) Rehabilitation of reaching after stroke: Task-related training versus progressive resistive exercise. Archives of Physical Medicine and Rehabilitation, 10, 1613-1618. http://dx.doi.org/10.1016/j.apmr.2004.01.028

[5] Greenwood, R.J., Barnes, M.P., McMillan, T.M. and Ward, C.D. (2003) Handbook of neurological rehabilitation. 2nd Edition, Psychology Press, New York.

[6] Hallett, M. (2001) Plasticity of the human motor cortex and recovery from stroke. Brain Research Reviews, 36,
169-174

http://dx.doi.org/10.1016/S0165-0173(01)00092-3

[7] Nelles, G., Jentzen, W., Jueptner, M., Muller, S. and Diener, H.C. (2001) Arm training induced brain plasticity in stroke studied with serial positron emission tomography. NeuroImage, 13, 1146-1154.

http://dx.doi.org/10.1006/nimg.2001.0757

[8] Classen, J., Liepert, J., Wise, S.P., Hallett, M. and Cohen, L.G. (1998) Rapid plasticity of human cortical movement representation induced by practice. Journal of Neurophysiology, 79, 1117-1123.

[9] Westlake, K. and Byl, N. (2013) Neural plasticity and implications for hand rehabilitation after neurological insult. Journal of Hand Therapy, 26, 87-92. http://dx.doi.org/10.1016/j.jht.2012.12.009

[10] Lindsay, M.P., Gubitz, G. and Bayley, M. (2010) Canadian best practice recommendations for stroke care. Canadian Stroke Strategy Best Practices and Standards Writing Group, Ottawa.

[11] Wolf, S.L., Winstein, C.J., Miller, J.P., Taub, E., Uswatte, G., Morris, D., et al. (2006) Effect of constraint-induced movement therapy on upper extremity function 3 to 9 months after stroke: The EXCITE randomized clinical trial. JAMA, 296, 2095-2104. http://dx.doi.org/10.1001/jama.296.17.2095

[12] Shi, Y.X., Tian, J.H., Yang, K.E. and Zhao, Y. (2011) Modified constraint-induced movement therapy versus traditional rehabilitation in patients with upper-extremity dysfunction after stroke: A systematic review and metaanalysis. Archives of Physical Medicine and Rehabilitation, 92, 972-982. http://dx.doi.org/10.1016/j.apmr.2010.12.036

[13] Taub, E., Uswatte, G., Bowman, M., Mark, V., Delgado, A., Bryson, C., et al. (2013) Constraint-induced movement therapy combined with chronic stroke patients with plegic hands: A case series. Archives of Physical Medicine and Rehabilitation, 94, 86-94. http://dx.doi.org/10.1016/j.apmr.2012.07.029

[14] Taub, E., Uswatte, G., King, D.K., Morris, D., Crage, J.E. and Chatterjee, A. (2006) A placebo-controlled trial of constraint-induced movement therapy for upper extremity after stroke. Stroke, 37, 1045-1049. http://dx.doi.org/10.1161/01.STR.0000206463.66461.97

[15] Page, S.J., Levine, P. and Leonard, A.C. (2005) Modified constraint-induced therapy in acute stroke: A randomized controlled pilot study. Neurorehabilitation and Neural Repair, 19, 27-32. http://dx.doi.org/10.1177/1545968304272701

[16] Rowe, T., Blanton, S. and Wolf, S. (2009) Long-term follow-up after constraint-induced therapy: A case report of a chronic stroke survivor. AJOT, 63, 317-322.

[17] Parker, V.M., Wade, D.T. and Langton-Hewer, R. (1986) Loss of arm function after stroke: Measurement, frequency, and recovery. International Rehabilitation Medicine, 8, 69-73.

[18] Nichols-Larsen, D., Clark, P.C., Zeringue, A., Greenspan, A. and Blanton, S. (2005) Factors influencing stroke survivors' quality of life during subacute recovery. Stroke, 36, 1480-1484. 
http://dx.doi.org/10.1161/01.STR.0000170706.13595.4f

[19] Barry, J.G., Ross, S.A. and Woehrle, J. (2012) Therapy incorporating a dynamic wrist-hand orthosis versus manual assistance in chronic stroke: A pilot study. Journal of Neurologic Physical Therapy, 36, 17-24. http://dx.doi.org/10.1097/NPT.0b013e318246203e

[20] Sun, S.F., Hsu, C.W., Hwang, C.W., Hsu, P.T., Wang, J.L. and Yang, C.L. (2006) Application of combined botulinum toxin type $\mathrm{A}$ and modified constraint-induced movement therapy for an individual with chronic upper-extremity spasticity after stroke. Physical Therapy, 86, 1387-1397. http://dx.doi.org/10.2522/ptj.20050262

[21] Butler, A., Blanton, S., Rowe, V. and Wolf, S. (2006) Attempting to improve function and quality of life using the FTM protocol: Case report. Journal of Neurologic Physical Therapy, 30, 148-156.

[22] Hoffman, H. and Blakey, G. (2011) New design of dynamic orthoses for neurological conditions. NeuroRehabilitation, 28, 55-61.

http://dx.doi.org/10.3233/NRE-2011-0632

[23] Jeon, H., Woo, Y., Yi, C., Kwon, O. Jung, M., Young-hee, L., et al. (2012) Effect of intensive training with a springassisted hand orthosis on movement smoothness in upper extremity following stroke: A pilot clinical trial. Topics in Stroke Rehabilitation 19, 320-328. http://dx.doi.org/10.1310/tsr1904-320

[24] Broeks, J.G., Lankhorst, G.J., Rumping, K. and Prevo, A.J. (1999) The long-term outcome of arm function after stroke: Results of a follow-up study. Disability and Rehabilitation, 21, 357-364. http://dx.doi.org/10.1080/096382899297459

[25] Evidence based research in stroke rehabilitation. (2013). http://www.ebrsr.com/ ebrsr/uploads/C_Motor_Recovery (PR).pdf

[26] Wissel, J., Ward, A.B., Erztgaard, P., Bensmail, D., Hecht, M.J., Lejeune, T.M., et al. (2009) European consensus table on the use of botulinum toxin type A in adult spasticity. Journal of Rehabilitation Medicine, 41, 13-25. http://dx.doi.org/10.2340/16501977-0303

[27] Naumann, M., So, Y., Argoff, C.E., Childers, M.K., Dykstra, D.D., Gronseth, G.S., et al. (2008) Assessment: botulinum neurotoxin in the treatment of autonomic disorders and pain (an evidence based review): Report of the therapeutics and technology assessment subcommittee of the American Academy of Neurology. Neurology, 70, 1707-1714. http://dx.doi.org/10.1212/01.wnl.0000311390.87642.d8

[28] Teasell, R., Foley, N., Pereira, S., Sequeira, K. and Miller, T. (2012) Evidence to practice: Botulinum toxin in the treatment of spasticity post stroke. Topics in Stroke Rehabilitation, 19, 115-121. http://dx.doi.org/10.1310/tsr1902-115

[29] Wolf, S., Milton, B., Reiss, A., Easley, K., Shenvi, N. and Clark, P. (2012) Further assessment to determine the additive effect of botulinum toxin type A on an upper extremity exercise program to enhance function among individuals with chronic stroke but extensor capability. Archives of Physical Medicine and Rehabilitation, 93, 578587. http://dx.doi.org/10.1016/j.apmr.2011.10.026

[30] Sun, S.F., Hsu, C.W., Sun, H.P., Hwang, C.W., Yang, C.L. and Wang, J.L. (2010) Combined botulinum toxin type A with modified constraint-induced movement therapy for chronic stroke patients with upper extremity spasticity: A randomized controlled study. Neurorehabilitation and Neural Repair, 24, 34-41.

http://dx.doi.org/10.1177/1545968309341060

[31] Marciniak, C. (2011) Poststrokehypertonicity: Upper limb assessment and treatment. Topics in Stroke Rehabilitation, 18, 179-194. http://dx.doi.org/10.1310/tsr1803-179

[32] Sheean, G., Lannin, N.A., Turner-Stokes, L., Rawicki, B. and Snow, B.J. (2010) Botulinum toxin assessment, intervention and after-care for upper limb hypertonicity in adults: International consensus statement. European Journal of Neurology, 17, 74-93.

http://dx.doi.org/10.1111/j.1468-1331.2010.03129.x 